\title{
Further Evidence for the Role of Nitric Oxide in Maternal Aggression: Effects of L-NAME on Maternal Aggression towards Female Intruders in Wistar Rats
}

\author{
S. ANKARALI ${ }^{1}$, H. C. ANKARALI ${ }^{2}$, C. MARANGOZ ${ }^{3}$ \\ ${ }^{1}$ Department of Physiology, Faculty of Medicine, University of Zonguldak Karaelmas, Esenkoy, \\ Zonguldak, ${ }^{2}$ Department of Biostatistics, Faculty of Medicine, University of Zonguldak Karaelmas, \\ Esenkoy, Zonguldak, ${ }^{3}$ Department of Physiology, Faculty of Medicine, University of Ondokuz \\ Mayis, Samsun, Turkey
}

Received March 17, 2008

Accepted June 23, 2008

On-line July 25, 2008

\begin{abstract}
Summary
It has been shown that nitric oxide (NO) increases aggression in male mice, whereas it decreases aggression in lactating female mice and prairie voles. It is also known that aggression can be exhibited at different levels in rodent species, strain or subtypes. The aims of this study were to investigate the proportion of aggressiveness in Wistar rats, the effect of intraperitoneally administered nonspecific nitric oxide synthase (NOS) inhibitor L-NAME ( $\mathrm{N}^{\mathrm{G}}$-nitro L-arginine methyl ester) on maternal aggression towards female intruders, and whether these effects are due to NO production or not. Rats were given saline intraperitoneally on the postpartum Day 2 and aggression levels were recorded. The same rats were given $60 \mathrm{mg} / \mathrm{kg}$ L-NAME or D-NAME ( $\mathrm{N}^{G}$-nitro D-arginine methyl ester) on the postpartum Day 3 and their effects on aggression levels were compared to saline. While L-NAME administration did not cause any differences in the total number of aggressive behavior, aggression duration and aggression intensity, it reduced the proportion of animals showing aggressive behavior. In addition, the latency of the first aggression was significantly increased by L-NAME. In the D-NAME group, however, no significant change was found. Our results have shown that L-NAME reduces maternal aggression towards female intruders in Wistar rats through inhibition of NO production. These results suggest that the role of $\mathrm{NO}$ in offensive and defensive maternal aggression shares neural mechanisms.
\end{abstract}

\section{Key words}

Maternal aggression - Nitric oxide $-\mathrm{N}^{G}$-nitro L-arginine methyl ester • Wistar rat

\section{Corresponding author}

S. Ankarali, Department of Physiology, Faculty of Medicine,
University of Duzce, 81000 Konuralp, Düzce, Turkey. Fax: +90 380 5421302. E-mail: seyitankarali@yahoo.com

\section{Introduction}

Lactating female mammals exhibit an aggressive behavior, which is called maternal aggression, to protect their pups towards male or female intruders to the nesting area (Erskine et al. 1980, Oliver and Young 2002). Temporarily increased aggression in lactating female is an outstanding feature only during the first two or three weeks after delivery. After the third week, it declines and later disappears even if the lactation continues (Erskine et al. 1980, Gandelman and Simon 1980, Siegel et al. 1983, Svare and Gandelman 1976). Although changes in several hormone and neurotransmitter (i.e. oxytocin, serotonin and dopamine) contents within the brain during this period have been shown, the underlying mechanisms still remain unclear (Consiglio et al. 2005, Giovenardi et al. 1998, Insel 1986, Nelson and Trainor 2007, Russel and Leng 1998, Svare 1990).

The number of studies to understand the role of $\mathrm{NO}$ in behavior has increased since it was determined that nitric oxide (NO) plays a role in many physiological and pathological processes as a neuronal messenger or neurotransmitter. The production of $\mathrm{NO}$ is catalyzed by NO synthase enzymes (NOS) (Moncada and Higgs 1993). There are at least three NOS isoenzymes which 
are extensively found in brain tissue: Type I (neuronal NOS; nNOS) in neurons, Type II (inducible NOS; iNOS) in glia cells and Type III (endothelial NOS, eNOS) in endothelial cells (Lincoln et al. 1997, Palmer et al. 1987).

The nNOS enzyme has a modulating role on male aggression in mice. When the production of NO is blocked via selective deletion of the nNOS gene $\left(\mathrm{nNOS}^{-/}\right)$or treatment with a specific nNOS inhibitor, 7-nitroindazole aggression increases (Demas et al. 1997, Nelson et al. 1995, Nelson and Trainor 2007). Additionally, as wild-type mice reduces aggression in response to submissive displays made by intruders, male $\mathrm{nNOS}^{-/-}$mice continues aggressive behavior in spite of submissive displays (Demas et al. 1997, Nelson and Trainor 2007). In contrast, eNOS ${ }^{-/-}$knockout male mice show dramatic decline in aggression (Demas et al. 1999). On the other hand, it seems that the role of NO in maternal aggression is different than in male aggression, at least in mice and prairie voles. It has been suggested that NO increases maternal aggression, whereas its blockade reduces attacks to the intruder in mice and prairie voles (Gammie et al. 2000a,b, Nelson et al. 1995, Nelson and Trainor 2007).

Maternal behaviors have some differences between mice and rats or laboratory and wild-type mice or more interestingly virgin and primiparous mice (Blanchard et al. 2003, Oliver and Young 2002, Russel and Leng 1998). It is possible that there are also some differences between the species, strains and even subtypes in terms of maternal aggression (Blanchard et al. 2003, Russel and Leng 1998). To claim the effectiveness of a drug on maternal aggression very definitively, therefore, it should be studied on different species, strains and subtypes. Some subjects may display no aggression in any circumstances, so they have been accepted as non-aggressive in some studies (Svare 1981, Brain 1990, Gammie and Nelson 2001). In a study, the proportion of non-aggressive animals has reported as $42 \% \quad(n=14)$ (Gammie and Nelson 2001). Another disputatious matter related to maternal aggression is about the type of this aggression, i.e. is it offensive or defensive? Some studies have suggested that the intruder sex affects the type of this aggression and its levels (Svare 1981, Brain 1990, Oliver and Young 2002).

Almost all previous studies which attempted to investigate the role of NO in maternal aggression used mice or prairie voles. There is only one study which investigated the effect of NO on maternal aggression in rats (Service and Woodside 2007). In the latter study, it has been shown that administration of $\mathrm{N}^{\mathrm{G}}$-nitro-Larginine methyl ester (L-NAME), a NO synthase inhibitor, into the third ventricle or the medial preoptic area disrupts maternal aggression. In this study and in many others, all subjects have randomly assigned to different groups, called between subject comparisons, regardless of whether they have exhibited maternal aggression to a male intruders naturally or not. They were compared with each other in terms of drug effects. In these groups, some subjects would be non-aggressive in all test conditions naturally. For eliminating this type of effect and genetic/environmental effects, we thought that the more appropriate study design would be a comparison within subjects, which compare measured variables in the pre- and post-treatment periods for each subject, instead of comparing between subjects.

In the present study, we aimed to investigate 1) the proportion of maternal aggression in Wistar rats, 2) the effects of intraperitoneally administered L-NAME, a nonspecific NOS inhibitor, on maternal aggression towards female intruders with more proper study design and 3) the effects of i.p. administered D-NAME, an ineffective enanthiomer of L-NAME, on maternal aggression and thereby whether the effects of L-NAME are due to NO production.

\section{Methods}

\section{Animals and housing}

Thirty-eight female Wistar rats (70-90 days old, body weight $242 \pm 23 \mathrm{~g}$ ) were used in this study. Animals were maintained in standard polycarbonate cages at ambient room temperature, and the light/dark cycle of room was set at 14/10 h. The floor was covered with wood shavings, which were used as bedding and nesting material. Food and water were provided ad libitum. Each female rat was housed with a stud male rat in the same cage and after the beginning of pregnancy; male rats were removed from the cages. All efforts were made to minimize animals' pain and discomfort. Experimental procedures were conducted with a government approval and according to local guidelines for the care and use of laboratory animals.

\section{Drugs and doses}

In this study, the effects of $\mathrm{N}^{\mathrm{G}}$-nitro-L-arginine methyl ester hydrochloride (L-NAME), a nonspecific NOS inhibitor, and its ineffective enanthiomer $\mathrm{N}^{\mathrm{G}}$-nitroD-arginine methyl ester hydrochloride (D-NAME) were 
investigated on maternal aggression. Animals were randomly divided into two groups as L-NAME $(n=20)$ and D-NAME $(n=18)$ groups. As treatment control, $0.5 \mathrm{ml}$ intraperitoneally (i.p.) saline was given to lactating rats and basal aggression levels were measured in both groups on Day 2. A dose of $60 \mathrm{mg} / \mathrm{kg}$ i.p. L-NAME or D-NAME, which can be considered as average effective dose in pharmacological studies were applied to animals on Day 3 (Uzbay et al. 1997, Uzbay and Kayir 2003, Yildirim and Marangoz 2004).

\section{Behavioral test}

Animals were tested for aggressive behavior using the resident-intruder paradigm, a well-characterized valid model of maternal aggression. The date of birth was considered postpartum Day 0. Aggression test was applied to the lactating female rat on postpartum Day 2 and Day 3 , because rats are maximally aggressive in the first lactation week towards female intruders and attack behavior is attenuated by the second lactation week (Haney et al. 1989). Tests were done between 08:00 and 12:00 a.m. on test days. On Day 2, i.p. saline was given to the resident rat $30 \mathrm{~min}$ before the experiment. The pups were removed from the home cage $3 \mathrm{~min}$ before the aggression test to prevent any harmful situation (Service and Woodside 2007, Siegel et al. 1983). Thirty minutes after saline injection an intruder female rat was placed into the home cage and then the aggressive behaviors of the resident rat were observed for $20 \mathrm{~min}$. To avoid any effects of contamination by intruder's odorant or familiarity, the cages were cleaned before test days and a different female rat was used in each test as the intruder. All intruders were selected among young virgins and their body sizes were smaller than lactating mothers. None of intruders was aggressive towards resident female rats.

Aggressive behaviors exhibited by lactating rat towards the intruder rat were observed and recorded according to the following parameters (Svare et al. 1981):

a) The latency to the first aggressive behavior: Time of first aggressive attack or posture exhibited towards the intruder. If there was not any aggressive behavior, total test time (1200 s) was used as data of the latency to the first aggressive behavior.

b) The number of aggressive behaviors: The number of aggressive behaviors which was exhibited towards the intruder rat.

c) The total duration of aggressive behaviors: Total amount of time for aggressive behaviors towards the intruder rat.

d) The intensity of aggressive behavior: Intensity of aggressive behavior exhibited by the resident rat was scored as follows. No aggressive manifestations (0); Intermittent mild aggressive posture or attack towards the intruder, no vocalizations (1); Intermittent intensive upright aggressive posture or attack or boxing with the intruder, vocalizations, but no biting or continuous fighting (2); Continuous fighting or attempts to bite the intruder rat, loud vocalizations (3).

On postpartum Day 3, the same test was repeated with L-NAME or D-NAME applications in L-NAME and D-NAME groups, respectively. The animals which did not exhibit any aggressive behavior by application both saline and L-NAME or D-NAME were accepted as non-aggressive.

\section{Statistical analysis}

Behavioral measurements, including the latency to first aggressive behavior (seconds), total number of aggressive behaviors, total duration of aggressive behaviors (seconds) and the intensity of aggressive behaviors were recorded as data. Descriptive statistics (mean \pm S.D., median and interquartile range - between $25 \%$ and $75 \%$ quartiles) of data were given in Tables. Kolmogorov-Smirnov test was used for normality. Wilcoxon paired signed rank test was used to compare saline versus L-NAME and saline versus D-NAME applications, because the data distribution was not normal and the variations among measurements were large. In addition, Mann-Whitney $U$ test was used to compare L-NAME and D-NAME groups about the measured variables. In addition, the differences between the proportions of exhibiting aggressive behavior in saline versus L-NAME and saline versus D-NAME applications were evaluated with McNemar test. Fisher exact test was used to show the difference between L-NAME and D-NAME groups about the aggressive animal proportion. If the $\mathrm{P}$ value obtained from calculations was smaller than 0.05 , the results would be accepted as statistically significant. SPSS (version 11.5) packet program was used in calculations.

\section{Results}

In this study, a resident-intruder paradigm was used to evaluate maternal aggression towards female intruders in the lactating rats. By using this paradigm, maternal aggression levels were measured on postpartum 
Table 1. Descriptive statistics of variables measured in L-NAME group.

\begin{tabular}{|c|c|c|c|}
\hline \multirow{2}{*}{$\begin{array}{l}\text { Treatment / } \\
\text { Measured Variables }\end{array}$} & Saline & L-NAME & $\mathbf{P}$ \\
\hline & $\begin{array}{l}\text { Mean } \pm \text { S.D. } \\
\text { Median }\left(\text { IR) }{ }^{\dagger}\right.\end{array}$ & $\begin{array}{l}\text { Mean } \pm \text { S.D. } \\
\text { Median (IR) }\end{array}$ & \\
\hline $\begin{array}{l}\text { The latency of first aggressive } \\
\text { behavior (s) }\end{array}$ & $\begin{array}{c}310.50 \pm 140.56 / \\
282(183.5-452.5)\end{array}$ & $\begin{array}{c}887.1 \pm 504.44 / \\
1200(191.25-1200)\end{array}$ & $0.017^{*}$ \\
\hline $\begin{array}{l}\text { The total number of aggressive } \\
\text { behavior }\end{array}$ & $\begin{array}{l}4.80 \pm 3.85 / \\
3(2.0-8.5)\end{array}$ & $\begin{array}{l}4.20 \pm 7.09 / \\
0(0-10.5)\end{array}$ & 0.646 \\
\hline $\begin{array}{l}\text { The total duration of aggressive } \\
\text { behaviors (s) }\end{array}$ & $\begin{array}{c}51.30 \pm 59.24 / \\
25(8.75-96.25)\end{array}$ & $\begin{array}{l}27 \pm 45.71 / \\
0(0-67.50)\end{array}$ & 0.139 \\
\hline The intensity of aggressive behavior & $\begin{array}{c}14.70 \pm 13.82 / \\
11(3.75-20.50)\end{array}$ & $\begin{array}{l}7.80 \pm 14.08 / \\
0(0-16)\end{array}$ & 0.139 \\
\hline
\end{tabular}

${ }^{*} \mathrm{P}<0.05$ (statistically significant); ${ }^{\dagger}$ IR: interquartile range.

Table 2. Descriptive statistics of variables measured in D-NAME group.

\begin{tabular}{|c|c|c|c|}
\hline \multirow{2}{*}{$\begin{array}{l}\text { Treatment / } \\
\text { Measured Variables }\end{array}$} & Saline & D-NAME & $\mathbf{P}$ \\
\hline & $\begin{array}{l}\text { Mean } \pm \text { S.D. } \\
\text { Median }\left(\text { IR) }{ }^{\dagger}\right.\end{array}$ & $\begin{array}{l}\text { Mean } \pm \text { S.D. } \\
\text { Median (IR) }\end{array}$ & \\
\hline $\begin{array}{l}\text { The latency of first aggressive } \\
\text { behavior (s) }\end{array}$ & $\begin{array}{c}252.2 \pm 199.56 / \\
165.0(125-414)\end{array}$ & $\begin{array}{c}233.0 \pm 176.05 / \\
202.5(102.5-345)\end{array}$ & 0.610 \\
\hline $\begin{array}{l}\text { The total number of aggressive } \\
\text { behavior }\end{array}$ & $\begin{array}{c}9.70 \pm 5.71 / \\
10(4.75-12.25)\end{array}$ & $\begin{array}{c}8.90 \pm 7.47 / \\
7(3.0-14.75\end{array}$ & 0.553 \\
\hline $\begin{array}{l}\text { The total duration of aggressive } \\
\text { behaviors (s) }\end{array}$ & $\begin{array}{c}53.0 \pm 36.51 / \\
45(27.50-69.75)\end{array}$ & $\begin{array}{c}52.30 \pm 41.67 / \\
37.5(24.5-80.5)\end{array}$ & 0.878 \\
\hline The intensity of aggressive behavior & $\begin{array}{c}13.40 \pm 12.71 / \\
9.50(4.75-17.25)\end{array}$ & $\begin{array}{c}12.30 \pm 12.99 / \\
6.5(3.0-24.25)\end{array}$ & 0.721 \\
\hline
\end{tabular}

${ }^{\dagger}$ IR: interquartile range.

Day 2 and 3 with applications of saline and $60 \mathrm{mg} / \mathrm{kg}$ i.p L-NAME $(n=20)$, respectively. The same protocol was carried out with D-NAME at $60 \mathrm{mg} / \mathrm{kg}$ i.p. dose in D-NAME group $(n=18)$.

The proportion of non-aggressive animals which did not exhibit any aggressive behavior during both saline and drug applications was $47 \%(18 / 38, n=38)$. They were excluded from other calculations of this study. Ten out of twenty remained animals belonged to L-NAME group and the other ten belonged to D-NAME group.

The aggressive animal proportion was reduced significantly by $70 \%(7 / 10, n=10)$ following L-NAME application $(\mathrm{P}=0.025)$, whereas it was reduced only by $10 \%(1 / 10, n=10)$ after D-NAME application $(\mathrm{P}=0.91)$ compared to previous saline injections which were accepted as control (Fig.1). L-NAME had more significant reducing effect on the aggressive animal proportion than D-NAME $(\mathrm{P}=0.02)$. A decrease in the aggression levels was detected in only one rat out of three which showed aggression in L-NAME group, whereas an increase was observed in the other two.

Results of statistical analysis which compared saline and drug applications are shown in Tables 1 and 2 . The latency of first aggressive behavior was significantly increased by L-NAME compared to saline injections $(\mathrm{P}=0.017)$. Aggression levels had a tendency to be reduced by the application of L-NAME in measured parameters such as total number, total duration and the intensity of aggressive behaviors in L-NAME group, but these effects were not statistically significant (Table 1). On the other hand, D-NAME did not cause any significant change in aggression levels compared to saline 


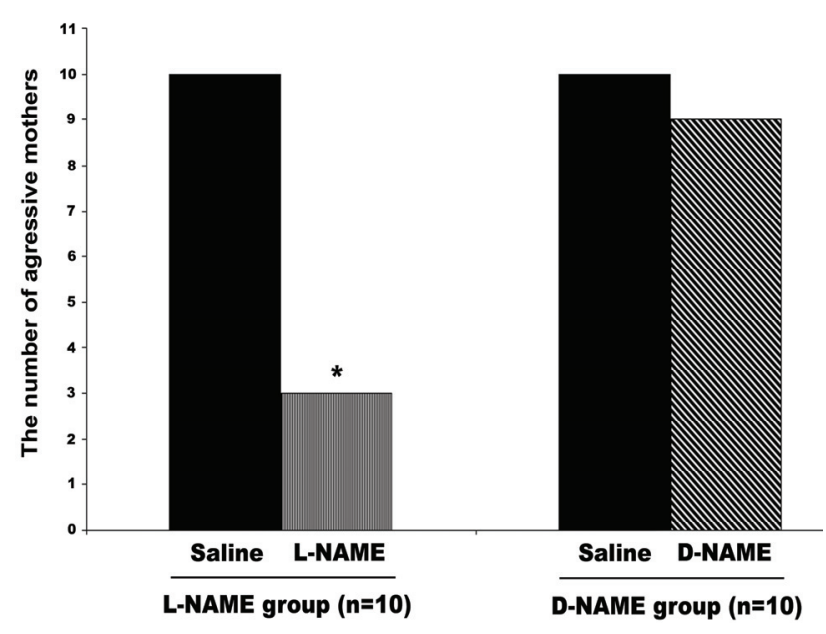

Fig. 1. Shows the effect of applying $60 \mathrm{mg} / \mathrm{kg}$ L-NAME or DNAME i.p. on maternal aggression in rats. L-NAME application reduced the proportion of mothers exhibiting aggression by $70 \%$ than saline application in L-NAME group $(\mathrm{P}=0.025, \mathrm{n}=10)$. However, the effect of D-NAME was found no statistically significant $(P=0.91, n=10) .{ }^{*} P<0.05$ statistically significant

injections (Table 2).

In addition, we compared L-NAME group versus D-NAME group on drug effectiveness. We found that L-NAME effect on parameters of maternal aggression was not different from that of D-NAME significantly, except the latency of first aggressive behavior which was significantly longer compared to D-NAME group $(\mathrm{P}=0.011)$.

\section{Discussion}

One of the most important findings of this study is that the systemic (i.p.) administration of L-NAME, a nonspecific NOS inhibitor, has reducing effects on maternal aggression towards female intruders in the lactating rats, while its ineffective enantiomer D-NAME has none. According to our findings, $60 \mathrm{mg} / \mathrm{kg}$ i.p. L-NAME significantly delayed the latency of first aggressive behavior. However, it reduced only nonsignificantly the total duration, total number and the intensity of aggressive behaviors. D-NAME was ineffective on all parameters of the aggression test. These results suggest that the reduce of maternal aggression resulting from systemically administered L-NAME might be due to inhibition of NO production in brain. Our results were similar to previous studies and have provided further evidence that NO might also be a necessary neuromodulator for expression of maternal aggression.

Another significant finding is the possibility that NO might have a role only on the starting of maternal aggression. Actually we can speculate on this possibility because L-NAME application affected significantly only the proportion of aggressive animals and the latency to the first attack compared to saline injections (Fig. 1). The other parameters of aggression did not change significantly because an increase in the aggression level was observed after L-NAME application in two rats, i.e. once maternal aggression started, it continued even more intensively. Perhaps, NO has different roles in the starting and the continuation of maternal aggression. Further detailed studies are needed to evaluate this possibility.

Gammie and Nelson (2001) have used naive wildtype house mice and found that the aggressive animal proportion was about $57 \%(n=14)$ in their study. Another study reported that the proportion of aggressive animal was about $75 \%$ in Wistar rats (De Almeida et al. 2005). We found in our laboratory that this proportion was $53 \%$ in Wistar rats. We excluded animals which were nonaggressive $(47 \%)$ in both saline and drug applications from all further statistical analysis, because we thought that they did not contribute to the aims of the study which was related to the effects of drugs on maternal aggression. These results showed that researchers have to consider this matter. Pretesting of animals is a useful method to eliminate non-aggressive animals.

In studies conducted so far, only indirect evidences exist about NO production and its levels in brain regions related to behavior in aggressive and nonaggressive animals (Gammie et al. 2000a,b, Nelson et al. 1995, Nelson and Trainor 2007). In these studies, NO production was inhibited either by using NOS inhibitors such as $7 \mathrm{Br}$-nitroindazole or by using $\mathrm{nNOS}^{-/-}$and eNOS ${ }^{-}$ 1- knockout mice. Citrulline-positive cells, which are indirect indicators of NO production, were counted in various regions of brain. According to the results obtained, in animals which show maternal aggressive behavior the number of citrulline-positive cells was found to be significantly higher compared to non-aggressive ones. There is a need to investigate in detail both NO level and the levels of other hormones and modulators which might affect maternal aggressive behavior in aggressive and non-aggressive animals. When different subjects are used in different groups, i.e. between subject designs, three confounded effects might appear. These negative effects are as follows: a) unknown baseline values, b) genetic differences, and c) environmental differences. Confounded effects cause bias in estimating drug effects. In the majority of studies investigating the role of NO on aggression, above mentioned experimental 
designs were used. The negative effects associated with those experimental designs may reduce the value of the results. Thus, We used a paired design to eliminate above mentioned confounded effects.

In previous studies using mice and prairie voles, it was reported that $\mathrm{NO}$ has an increasing effect on maternal aggression but a reducing effect on male aggression (Gammie et al. 2000b, Nelson et al. 1995). Therefore, the results of this study are consistent with previous studies and provide further evidence that NO has an increasing role in maternal aggression of other rodent species such as mice and prairie voles. There is only one study about the role of NO in maternal aggression of rats. This study has revealed that the application of $250 \mu \mathrm{g}$ L-NAME (the highest dose) into the third ventricle and application of $40 \mu \mathrm{g}$ L-NAME (the highest dose) into the medial preoptic area disrupt maternal aggression (Service and Woodside 2007). In our study which examined the effects of systemic application of L-NAME, similar results were obtained. Reducing effect of L-NAME on maternal aggression may have occurred either via direct inhibition of NO secretion in the related brain regions or indirectly by changing the secretion of other hormones and neurotransmitters modulated by NO. Further studies are needed to ascertain the relations between these hormones and neurotransmitters and NO secretion.

Another difference of our study from previous studies is the sex of the intruder. Maternal aggression is generally considered as defensive behavior but it has been suggested that maternal aggression is a heterogeneous phenomenon ranging from offensive to defensive attack according to the intruder sex (Brain 1990, Oliver and Young 2002). Sexually naive males show particularly intense defensive attacks, whereas virgin and other female intruders show offensive attacks. Rats are maximally aggressive in the first lactation week towards female intruders, whereas mice are more aggressive towards male intruders (Brain 1990). Our study has been the first in which female intruders were used and the effects of L-NAME on maternal aggression were similar as in studies in which male intruders were used. NO may have similar neural circuits in offensive and defensive type aggression in the lactating rats.

The study had some limitations. The first is the probability of the effects of L-NAME on maternal aggression via changes in blood pressure and brain blood flow. Although, it is known that nonspecific NOS inhibitor L-NAME causes an increase in blood pressure, there is no certain information that hypertension reduces aggression in animals (Huang et al. 1995). Furthermore, no reduction of the aggression has been observed by hypertension treatment in hypertensive $\mathrm{eNOS}^{-/}$knockout male mice (Gammie et al. 2000a). Another evidence for blood pressure-independent effect of L-NAME are similar results obtained in aggression studies with specific nNOS inhibitor 7-nitroindazole (Gammie et al. 2000b). The second limitation of the study is the possibility that LNAME may decrease the locomotor activity. However, our previous experiences as well as several reports indicate that NOS inhibitors such as L-NAME $(60 \mathrm{mg} / \mathrm{kg}$ i.p.) produce no significant effect on spontaneous locomotor activity of rodents (Celik et al. 1999, Johansson et al. 1997, Kaputlu and Uzbay 1997, Uzbay and Kayir 2003). Another limitation may be the order effect of test days because aggression may decrease over time, rather than due to any effects attributable to the drug, but we did not find any significant order effect of test days in our unpublished study. On the other hand, there are many studies which report that maternal aggression does not decline in the first week after delivery (Haney et al. 1989, Mayer 1987, Oliver and Young 2002).

There are specific neural substrates in animal brain subserving different functions in agonistic behavior, and similar mechanisms are probably also available in the human brain (Oliver and Young 2002). In a study on humans, Rujescu et al. (2008) showed that some NOS-I haplotypes (C-G-G and G-G) are associated with increased aggression in suicide attempters, some others like C-T-A, T-A and the rs 891512 haplotypes of NOS-III are associated with decreased anger-related behavior.

In conclusion, our study showed that systemic application of nonspecific NOS inhibitor L-NAME, but not D-NAME, decreases maternal aggression in Wistar rats. This result provides further evidence that $\mathrm{NO}$ might be one of the possible mediators of maternal aggression in rats. NO may have a role in offensive maternal behaviors as well as defensive. There might be some confounding effects in maternal aggression studies and therefore a paired study design is more proper to investigate drug effects.

\section{Conflict of Interest}

There is no conflict of interest.

\section{Acknowledgements}

We would like to thank Nafiye Çiğdem Aktekin for her help in polishing English. 


\section{References}

BLANCHARD RJ, WALL PM, BLANCHARD DC: Problems in the study of rodent aggression. Horm Behav 44: 161$170,2003$.

BRAIN PF: Variation in aggressiveness in house mouse populations. Biol J Linn Soc 41: 257-269, 1990.

CELIK T, ZAGLI U, KAYIR H, UZBAY IT: Nitric oxide synthase inhibition blocks amphetamine-induced locomotor activity in mice. Drug Alcohol Depend 56: 109-113, 1999.

CONSIGLIO AR, BORSOI A, PEREIRA GAM, LUCION AB: Effects of oxytocin microinjected into the central amygdaloid nucleus and bed nucleus of stria terminalis on maternal aggressive behavior in rats. Physiol Behav 85: 354-362, 2005.

DE ALMEIDA RMM, GIOVENARDI M, DA SILVA SP, DE OLIVEIRA VP, STEIN DJ: Maternal aggression in Wistar rats: effect of $5-\mathrm{HT}_{2 \mathrm{~A} / 2 \mathrm{C}}$ receptor agonist and antagonist microinjected into the dorsal periaqueductal gray matter and medial septum. Braz J Med Biol Res 38: 597-602, 2005.

DEMAS GE, ELIASSON MJ, DAWSON TM, DAWSON VL, KRIEGSFELD LJ, NELSON RJ, SNYDER SH: Inhibition of neuronal nitric oxide synthase increases aggressive behavior in mice. Mol Med 3: 610-616, 1997.

DEMAS GE, KRIEGSFELD LJ, BLACKSHAW S, HUANG P, GAMMIE SC, NELSON RJ, SNYDER S: Elimination of aggressive behavior in male mice lacking endothelial nitric oxide synthase. J Neurosci 19 RC30: 1-5, 1999.

ERSKINE MS, BARFIELD RJ, GOLDMAN BD: Postpartum aggression in rats: I. Effects of hypophysectomy. $J$ Comp Physiol Psychol 94: 484-494, 1980.

GAMMIE SC, NELSON RJ: cFOS and pCREB activation and maternal aggression in mice. Brain Res 898: 232-241, 2001.

GAMMIE SC, HUANG PL, NELSON RJ: Maternal aggression in endothelial nitric oxide synthase-deficient mice. Horm Behav 38: 13-20, 2000a.

GAMMIE SC, OLAGHERE-DA SILVA UB, NELSON RJ: 3-Bromo-7-nitroindazole, a neuronal nitric oxide synthase inhibitor impairs maternal aggression and citrulline immunoreactivity in prairie voles. Brain Res 870: 80-86, 2000b.

GANDELMAN R, SIMON NG: Postpartum fighting in the rat: nipple development and the presence of young. Behav Neural Biol 28: 350-360, 1980.

GIOVENARDI M, PADOIN MJ, CADORE LP, LUCION AB: Hypothalamic paraventricular nucleus modulates maternal aggression in rats: effect of ibotennic acid lesion and oxytocin antisense. Physiol Behav 63: 351-359, 1998.

HANEY M, DEBOLD JR, MICZEK KA: Maternal aggression in mice and rats towards male and female conspecifics. Aggressive Behav 15: 443-453, 1989.

HUANG PL, HUANG Z, MASHIMO H, BLOCH KD, MOSKOWITZ MA, BEVAN JA, FISHMAN MC: Hypertension in mice lacking the gene for endothelial nitric oxide synthase. Nature 377: 239-242, 1995.

INSEL TR: Post partum increases in brain oxytocin binding. Neuroendocrinology 44: 515-518, 1986.

JOHANSSON C, JACKSON DM, SVENSON L: Nitric oxide synthase inhibition blocks phencyclidine-induced behavioral effects on prepulse inhibition and locomotor activity in the rat. Psychopharmacology 131: 167-173, 1997.

KAPUTLU I, UZBAY IT: L-NAME inhibits pentylenetetrazole and strychinine-induced seizures in mice. Brain Res 753: 98-101, 1997.

LINCOLN J, HOYLE C, BURNSTOCK G: Nitric Oxide in Health and Disease. Cambridge University Press, Cambridge, 1997.

MAYER AD, REISBICK S, SIEGEL HI, ROSENBLATT JS: Maternal aggression in rats: changes over pregnancy and lactation in a sprague-dawley strain. Aggressive Behav 13: 29-43, 1987.

MONCADA S, HIGGS A: The L-arginine-nitric oxide pathway. N Engl J Med 329: 2002-2012, 1993.

NELSON RJ, TRAINOR BC: Neural mechanisms of aggression. Nat Rev Neurosci 8: 536-546, 2007.

NELSON RJ, DEMAS GE, HUANG PL, FISHMAN MC, DAWSON VL, DAWSON TM, SNYDER SH: Behavioural abnormalities in male mice lacking neuronal nitric oxide synthase. Nature 378: 383-386, 1995. 
OLIVER B, YOUNG LJ: Animal models of aggression. In: Neuropsychopharmacology: The Fifth Generation of Progress. KL DAVIS, D CHARNEY, JT COYLE, C NEMEROFF (eds). American College of Neuropsychopharmacology, New York, 2002, pp 1699-1708.

PALMER RMJ, FERRIGE AG, MONCADA S:. Nitric oxide release accounts for the biological activity of endothelium-derived relaxing factor. Nature 327: 524-526, 1987.

RUJESCU D, GIEGLING I, MANDELLI L, SCHNEIDER B, HARTMANN AM, SCHNABEL A, MAURER K, MÖLLER H, SERRETTI A: NOS-I and -III gene variants are differentially associated with facets of suicidal behavior and aggression-related traits. Am J Med Genet B Neuropsychiatr Genet 147: 42-48, 2008.

RUSSELL JA, LENG G: Sex, parturition and motherhood without oxytocin? J Endocrinol 157: 343-359, 1998.

SERVICE G, WOODSIDE B: Inhibition of nitric oxide synthase within the medial preoptic area impairs pup retrieval in lactating rats. Behav Neurosci 121: 140-147, 2007.

SIEGEL HI, GIORDANO AL, MALLAFRE CM, ROSENBLATT JS: Maternal aggression in hamsters: effects of stage of lactation presence of pups, and repeated testing. Horm Behav 17: 86-93, 1983.

SVARE B: Maternal aggression: hormonal, genetic, and developmental determinants. In: Mammalian Parenting: Biochemical, Neurobiological and Behavioral Determinants. NA KRASNEGOR, RS BRIDGES (eds), Oxford UP, New York,1990, pp 118-132.

SVARE B, GANDELMAN R: Suckling stimulation induces aggression in virgin female mice. Nature 260: 606-608, 1976.

SVARE B, BETTERIDGE C, KATZ D, SAMUELS O: Some situational and experimental determinants of maternal aggression in mice. Physiol Behav 26: 253-258, 1981.

UZBAY IT, ERDEN BF, TAPANYIGIT EE., KAYAALP SO: Nitric oxide synthase inhibition attenuates signs of ethanol withdrawal in rats. Life Sci 61: 2197-2209, 1997.

UZBAY IT, KAYIR H: Bromocriptine and quinpirole, but not 7-OH-DPAT or SKF 38393, potentiate the inhibitory effect of L-NAME on ethanol-induced locomotor activity in mice. Naunyn-Schmiedebergs Arch Pharmacol 367: 414-421, 2003.

YILDIRIM M, MARANGOZ C: Effects of nitric oxide on passive avoidance learning in rats. Int J Neurosci 114: 597606, 2004. 